\title{
Değişik Tipteki Agrega ve Bağlayıcının Sıcak Karışım Asfaltın Mekanik Özelliklerine Etkisi
}

\author{
Remzi Naml1 ${ }^{1 *}$, Merva Görgülü ${ }^{2}$ \\ 1*rnamli@firat.edu.tr Fırat Üniversitesi Teknik Bilimler Meslek Yüksekokulu Elazı̆̆/Türkiye, Orcid No: 0000-0002-2891-1012 \\ ²mervagorgulu@gmail.com Kahramanmaraş/Türkiye
}

(International Conference on Design, Research and Development (RDCONF) 2021 - 15-18 December 2021)

(DOI: 10.31590/ejosat.1041688)

ATIF/REFERENCE: Namlı, R. \& Görgülü, M. (2021). Değişik Tipteki Agrega ve Bağlayıcının Sıcak Karışım Asfaltın Mekanik Özelliklerine Etkisi. Avrupa Bilim ve Teknoloji Dergisi, (32), 1054-1065.

\section{$\ddot{O} \mathbf{z}$}

Bu çalışmada, değişik tipteki agrega ve bağlayıcının sıcak karışım asfaltın mekanik özelliklerine etkisi deneysel olarak incelenmiştir. Çalışmada kalker, bazalt ve dere malzemesi olarak 3 tip agrega kullanılmıştır. Kalker Elazığ İli Kömürhan Taş Ocağı'ndan, bazalt Elazı̆̆ İli Harput Beton Taş Ocağı'ndan, Dere malzemesi ise Bingöl İli Genç-Murat Kum-Çakıl Ocağı'ndan temin edilmiştir. Bağlayıcı olarak Batman Rafinerisi'nden temin edilen 2 tip bitümlü bağlayıcı (B 50/70 ve B 160/220) kullanılmıştır. Kalker, bazalt, dere malzemesi ve kalker + dere malzemesi olan her agrega grubu için \% 4, \% 4,5, \% 5, \% 5,5, \% 6 oranlarında 2 tip bitümlü bağlayıcı kullanılarak asfalt karışımları hazırlanmıştır. Karışımların optimum bitüm oranları Marshall deneyleri yapılarak belirlenmiş ve bu deneyler sonucunda karışımların mekanik özellikleri değerlendirilmiştir. Bununla birlikte karışımların stabilite, akma, yoğunluk ve boşluk değerleri karşılaştırmalı olarak irdelenmiştir. Bu çalışma sonucunda elde edilen bulgulardan, bitüm ihtiyacının az olması, ekonomi ve stabilite bakımından diğer karışımlardan avantajlı olması, Marshall dizayn parametre değerlerinin sınır şartları sağlaması sebebiyle agrega grubu kalker ve bitümlü bağlayıcısı B 160/220 olan karışımın daha iyi sonuçlar verdiği açıkça gözlenmiştir.

Anahtar Kelimeler: Agrega, Bitümlü Bağlayıcı, Marshall Deneyi, Mekanik Özellikler

\section{The Effect of Different Aggregates and Binder Types on the Mechanical Properties of Hot Mix Asphalt}

\begin{abstract}
In this study, the effect of different aggregates and binder types on the mechanical properties of hot mix asphalt has been investigated experimentally. Three types of aggregate were used as limestone, basalt and creek material in the study. Limestone from Elazı g city Kömürhan quarry, basalt from Elazı ̆̆ city Harput concrete quarry and stream material from Bingöl city Genç-Murat sand gravel quarry were provided. Two types of bituminous binders supplied from Batman Refinery (B 50/70 and B 160/220) were used as binders. Asphalt mixtures were prepared using 2 types of bituminous binders in $4 \%, 4.5 \%, 5 \%, 5.5 \%$ and $6 \%$ ratios for each aggregate group of limestone, basalt, creek material and limestone + creek material. The optimum bitumen ratios of the mixtures were determined by Marshall experiments and the mechanical properties of the mixtures were evaluated. In addition, the stability, flow, density and void values of the mixtures are discussed comparatively. From the results obtained from this study,It was clearly observed that the aggregate group limestone and bituminous binder B 160/220 mixture gave better results because Marshall design parameter values had boundary condition, low bitumen requirement, economical and stability advantages.
\end{abstract}

Keywords: Aggregate, Bituminous Binder, Marshall Test, Mechanical Properties.

\footnotetext{
* Sorumlu Yazar: rnamli@ firat.edu.tr
} 


\section{Giriş}

Ülkemizde yük taşımacılığının \% 70’i, yolcu taşımacılığının da \% 90’ı karayolu ile yapılmaktadır. Özellikle 1950'li yıllardan sonra, karayolu yapımı artmış ve ulaşım araçları çoğalmıştır. Trafik hacmi ve dingil yüklerindeki bu aşırı artış, yol üst yapısını tahrip etmesi sebebiyle daha çok ve ağır araç taşıyabilen yeni yolların yapımını sürekli olarak zorunlu kılmaktadır. Yeni yapılacak yolların güvenlik, estetik, konfor gibi faktörlere uygun inşa edilmesi kaliteli yap1 malzemesiyle mümkündür [1].

Her gün artan ağır taşıt trafiği yollarımızı erken ve yapısal olarak tahrip edip bu yöndeki çabaların beton asfalt kaplamalı yol uzunluğunu artırmaktan çok, bakım onarıma harcanmasına neden olmaktadır. $\mathrm{Bu}$ nedenle mühendisler daha sağlam, uzun süre bakım onarıma ihtiyaç göstermeyecek karışım tasarımları yapmak için çaba sarf etmektedirler [2].

Agrega ile bitümlü malzeme bileşiminden meydana gelen ve trafik yüklerine doğrudan maruz kalan kaplama tabakası, trafiğin aşındırma ve iklimin ayrıştırma etkilerine karşı direnç göstermek, yol yapısını sudan korumak ve düzgün bir yuvarlanma yüzeyi sağlayarak konforlu bir sürüş sağlamak amacıyla, Sathi Kaplama veya Bitümlü Sıcak Karışım (BSK) Kaplama olarak inşa edilmektedir [3].

Bitümlü Sıcak Karışım (BSK)'lar, çok iyi servis performans1, sürüş konforu, stabilite, durabilite ve suya karşı dayanım sağlaması yönüyle yol üst yapılarında en çok kullanılan kaplama türüdür. [4].

Yol yapımında kullanılan agregalardan kalkerin bazik, bazaltın ise nötür olduğu kabul edilmektedir. [5].

BSK'ların yüksek kalitede imal edilmeleri gerektiği için stabilite, rijitlik, dayanıklılık, yorulma, işlenebilirlik gibi fiziksel ve mekanik özelliklerinin tümünü ideal olarak sağlayabilecek karışım tasarımlarının yapılması büyük önem arz etmektedir [6].

Geçmişten bugüne daha sağlam, ön görülen süre içerisinde trafik ve çevre şartlarının aşındırıcı etkilerine direnç gösterebilecek yolların inşası için büyük bir çaba sarf edilmekte, bu amaçla üstyapıyı oluşturan her bir tabakanın deneysel ve sayısal analizleri yapılarak stabilitesi ve durabilitesi yüksek karışımlar ve tabakalar elde edilmeye çalışılmaktadır [6].

Bitümlü sıcak karışımlarda kohezyon, bitümlü bağlayıcı tarafından karşılanırken agrega ise karışımın içsel sürtünme direncini ve stabilitesini sağlamaktadır. Bitümlü bağlayıcılar, BSK'larda ağırlıkça \% $\quad 5-7$ gibi düşük bir oranında kullanılmasına rağmen karışım performansı üzerinde çok büyük etkiye sahiptir [7].

Yollardaki aşınma tabakası (en üst tabaka) yol güvenliği açısından en önemli tabakadır. Yolun hizmet ömrünü güvenli bir şekilde tamamlaması için, kullanılan agregaların, sürtünme katsayılarının yüksek olması ve hizmet ömrü boyunca cilalanmaya karşı yüksek dayanım sağlaması istenir. Bunu sağlamak için asfalt karışımlarda kullanılan agregaların mekanik özellikleri oldukça iyi olmalıdır [8].

BSK içerisinde yer alan malzemelerin, tipleri özellikleri miktarları ve hazırlanma şartları bu karışımın hizmet ömrü boyunca sahip olacağı performansı belirlemektedir. Kullanılacak malzemelerin özellikleri, çevresel şartlar, kaplamanın sıkışabilirliğine ve dolayısıyla rijitliğine etki ederek üst yapının performansını belirlemektedir [9].

Bu çalışmada, değişik tipteki agrega ve bağlayıcının sıcak karışım asfaltın mekanik özelliklerine etkisi deneysel olarak incelenmiştir. Tasarım yöntemi olarak da Marshall Tasarım Yöntemi kullanılmıştır.

\section{Materyal ve Metot}

Çalışmada materyal olarak kırmataş agregalar ve bitümlü bağlayıcılar kullanılmıştır. Kullanılan materyallere ait bilgiler aşağıda verilmiştir.

\section{1. Çalışmada Kullanılan Agregalar}

Bu çalışmada kalker, bazalt ve dere malzemesi olarak 3 tip agrega kullanılmıştır. Kalker Elazığ İli Kömürhan Taş Ocağı'ndan, bazalt Elazığ İli Harput Beton Taş Ocağı'ndan, Dere malzemesi ise Bingöl İli Genç-Murat Kum-Çakıl Ocağı'ndan temin edilmiştir.

\section{2. Çalışmada Kullanılan Bitümler}

Bağlayıcı olarak Batman Rafinerisi'nden temin edilen 50/70 ve 160/220 penetrasyonlu 2 tip bitümlü bağlayıcı kullanılmıştır.

\subsection{Metot}

Bu çalışmada, Karayolu Teknik Şartnamesi (KTŞ) 2013 Kısım 407 Asfalt Betonu Binder ve Aşınma Tabakları başlı̆̆ı adı altında belirtilen kriterler ve standartlar göz önüne alınmıştır.

Deneysel çalışmalarda karışımların agrega gradasyonunu belirlemek için KTŞ (2013)'te belirtilen Tablo 2.1'de gösterilen Binder Tabakası için gradasyon limitleri kullanılmıştır. Yine bitümlü sıcak karışım dizaynı için KTŞ (2013)'te belirtilen Tablo 2.2 'te gösterilen Binder Tabakası asfalt betonu dizayn kriterleri dikkate alınmıştır.

Tablo 2.1. Binder Tabakası gradasyon limitleri [10].

\begin{tabular}{|c|c|}
\hline Elek Boyu mm (in, No) & \% Geçen \\
\hline $25(1$ ') & $80-100$ \\
\hline $19(3 / 4 ")$ & $58-80$ \\
\hline $12,5(1 / 2 ")$ & $48-70$ \\
\hline $9,5(3 / 8 ”)$ & $30-52$ \\
\hline $4,75($ No.4) & $20-40$ \\
\hline $2,00($ No.10) & $8-22$ \\
\hline $0,425($ No.40) & $5-14$ \\
\hline $0,075($ No. 0.200$)$ & $2-7$ \\
\hline
\end{tabular}


Tablo 2.2. Asfalt betonu dizayn kriterleri [10].

\begin{tabular}{|l|c|c|c|}
\hline \multirow{2}{*}{\multicolumn{1}{|c|}{ Özellikler }} & \multicolumn{2}{c|}{ Binder } & \multirow{2}{*}{ Deney Standardı } \\
\cline { 2 - 3 } & \multicolumn{2}{|c|}{ Min. } & \multicolumn{2}{|c|}{ Maks. } & \\
\hline Briket yapımında uygulanacak darbe sayıs1 & \multicolumn{2}{|c|}{75} & TS EN 12697-30 \\
\hline Marshall stabilitesi, kg & 750 & - & TS EN 12697-34 \\
\hline Boşluk, \% & 4 & 6 & TS EN 12697-8 \\
\hline Asfalt dolu boşluk, \% & 60 & 75 & TS EN 12697-8 \\
\hline Agregalar arası boşluk (VMA), \% & 13 & 15 & TS EN 12697-8 \\
\hline Akma, mm 10'-2 in. & $2(8)$ & $4(16)$ & TS EN 12697-34 \\
\hline Filler/Bitüm oranı & - & 1,4 & \\
\hline Bitüm (ağırlıç̧a, 100'e) & 3,5 & 6,5 & TS EN 12697-1 \\
\hline
\end{tabular}

Deneysel çalışmalarda Marshall Tasarım Yöntemi için hazırlanan bitümlü sıcak karışımlarda kullanılan malzemelerin türü ve sonuçların sunulması için karışımların kısa adlandırılması Tablo 2.3 ’te gösterilmiştir.

Tablo 2.3. Marshall Tasarım Yönteminde kullanılan malzemelerin türü ve adlandırılması

\begin{tabular}{|c|c|c|}
\hline Agrega Türü & Bitümlü Bağlayıcı Türü & Adlandırma \\
\hline Kalker & 50/70 penetrasyonlu bitüm & K 1 \\
\hline Kalker & 160/220 penetrasyonlu bitüm & K 2 \\
\hline Bazalt & 50/70 penetrasyonlu bitüm & B 1 \\
\hline Bazalt & 160/220 penetrasyonlu bitüm & B 2 \\
\hline Dere malzemesi & 50/70 penetrasyonlu bitüm & D 1 \\
\hline Dere malzemesi & 160/220 penetrasyonlu bitüm & D 2 \\
\hline $\begin{array}{c}\text { Kalker + Dere malzemesi } \\
\text { (Bir briket için agrega } \\
\text { ağırlığındaki (1150 gr ) } \\
\text { karışım oranları \% 50'e } \\
\% 50 \text { 'dir.) }\end{array}$ & 50/70 penetrasyonlu bitüm & KD 1 \\
\hline $\begin{array}{c}\text { Kalker + Dere malzemesi } \\
\text { (Bir briket için agrega } \\
\text { ağırlığındaki (1150 gr ) } \\
\text { karışım oranları \% 50'e } \\
\% 50 \text { 'dir.) }\end{array}$ & $160 / 220$ penetrasyonlu bitüm & KD 2 \\
\hline
\end{tabular}

\subsection{Marshall Tasarım Yöntemi}

BSK'ların dizayn edilmesinde Marshall metodu olarak bilinen Marshall stabilite ve akma deneyi kullanılmaktadır. Bu metot, "American Society for Testing and Materials" tarafindan standart haline getirilmiş ve metot ASTM D-1559'da verilmiştir. Ülkemizde de bu deney TS EN 12967-34 standardına göre yapılmaktadır $[59,60]$. Bu standartta stabilite; yükleme sonucu meydana gelen deformasyona karşı maksimum dayanım miktarı olarak, akma ise yükleme esnasında maksimum yüke ulaşıldığı andaki numunede meydana gelen deformasyon miktarı olarak tanımlanmaktadır [11].

Metot, sıcak karışımların laboratuvar dizaynı ve sıcak karışım asfalt kaplamalarının uygulamadaki kontrolleri için kullanılır [12]. Bu çalışmada da karışım dizayn metodu olarak Marshall Metodu kullanılmıştır.

Çalışmada kullanılan agregalar için asfalt betonu karışım numunelerinin hazırlanmasında KTŞ (2013)'te belirtilen Binder Tabakası gronülometri sınırları arasında kalan agrega karışımı kullanılmıştır. Taşocaklarından alınan agregalar öngörülen granülometri için elemeye tabi tutularak bir numune için gerekli malzeme miktarlarına ilişkin her bir elek üzerinde kalan miktar ve şartname sınır değerleri Tablo 2.4'de verilmiștir.

Çalışma kapsamında yapılan tüm deneylerde kullanılan karışım numuneleri Şekil 2.1'de verilen agrega gronülometrisi kullanılarak hazırlanmıştır. 
European Journal of Science and Technology

Tablo 2.4. Karışımlarda kullanılan agrega granülometrisi ve şartname sınırları

\begin{tabular}{|c|c|c|c|c|c|}
\hline \multicolumn{2}{|c|}{ Elek boyutu } & $\begin{array}{c}\text { Şartname sinırları } \\
\text { toplam geçen }\end{array}$ & $\begin{array}{c}\text { Karışım granülometrisi } \\
\text { toplam geçen }\end{array}$ & $\begin{array}{c}\text { Elek üzerinde } \\
\text { kalan }\end{array}$ & $\begin{array}{c}\text { Bir numune için } \\
\text { kullanılan miktar }\end{array}$ \\
\hline Inch & Mm & $\%$ & $\%$ & $\%$ & Gr \\
\hline$(1 ")$ & 25 & 100 & 100 & 0 & 0 \\
\hline$(3 / 4 ")$ & 19 & $80-100$ & 90 & 10 & 115,0 \\
\hline$\left(1 / 2^{\prime \prime}\right)$ & 12,5 & $58-80$ & 69 & 21 & 241,5 \\
\hline$\left(3 / 8^{\prime \prime}\right)$ & 9,5 & $48-70$ & 59 & 10 & 115,0 \\
\hline No:4 & 4,75 & $30-52$ & 41 & 18 & 207,0 \\
\hline No:10 & 2,00 & $20-40$ & 30 & 11 & 126,5 \\
\hline No:40 & 0,425 & $8-22$ & 15 & 15 & 172,5 \\
\hline No:80 & 0,180 & $5-14$ & 10 & 5 & 57,5 \\
\hline No:200 & 0,075 & $2-7$ & 4 & 6 & 69,0 \\
\hline Tava & - & - & 0 & 4 & 46,0 \\
\hline \multicolumn{7}{r|}{} & Toplam & & 100 & 1150,0 \\
\hline
\end{tabular}

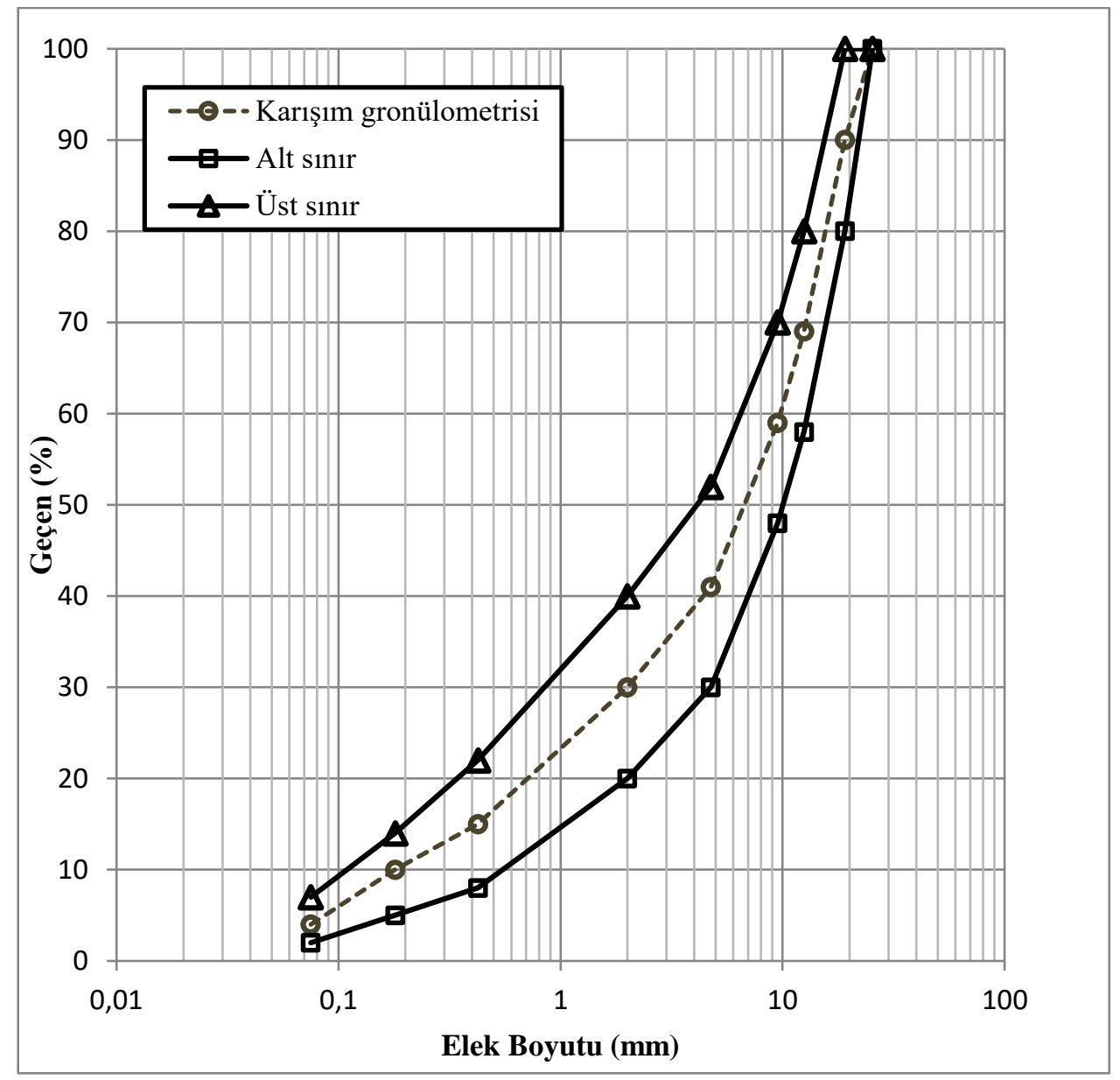

Şekil 2.1. Çalışmada kullanılan agrega gronülometrisi

\section{Deneysel Çalışma}

Karışım numunelerinde agrega türü olarak K'lar kalkerin, B'ler bazaltın, D'ler dere malzemesinin ve KD'ler kalker + dere malzemesinin kullanıldığını göstermektedir. Verilen numara olarak karışımlarda 1, 50/70 penetrasyonlu bitümlü bağlayıcının kullanıldığını 2, 160/220 penetrasyonlu bitümlü bağlayıcının kullanıldığını göstermektedir. Bunun neticesinde karışımlar ise $\mathrm{K}$ 1, K 2, B 1, B 2, D 1, D 2, KD 1 ve KD 2 olarak adlandırılmaktadır.
K 1 ve K 2 karışımlarına ait Marshall dizayn sonuçları yardımıyla elde edilen Dp - Wa, Stabilite - Wa, , Vh - Wa, , Vf Wa, Akma - Wa, VMA - Wa grafikleri Şekil 3.1'de sırasıyla gösterilmektedir. 


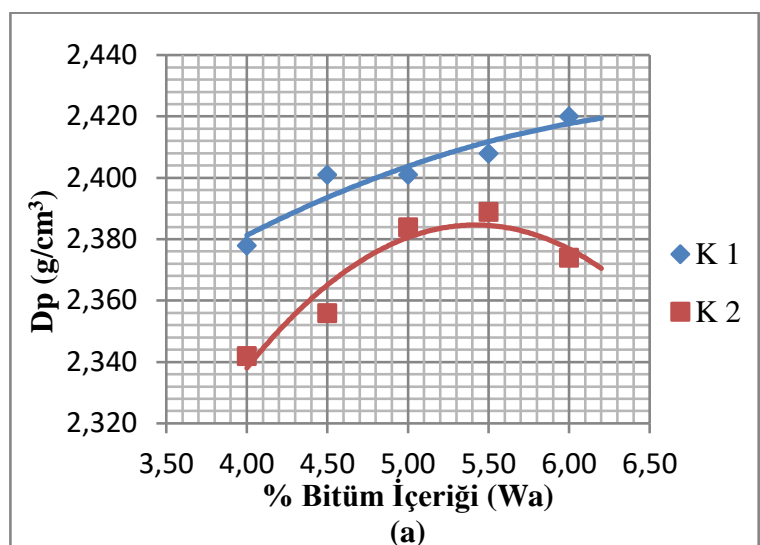

(a)

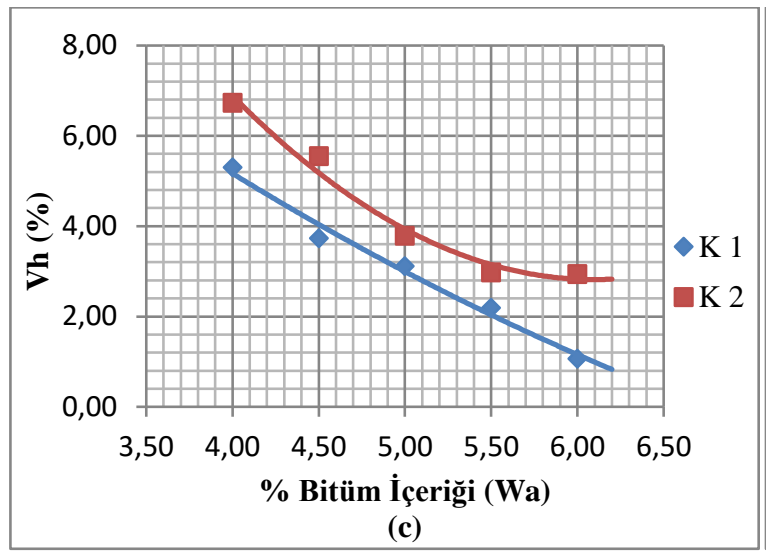

(c)

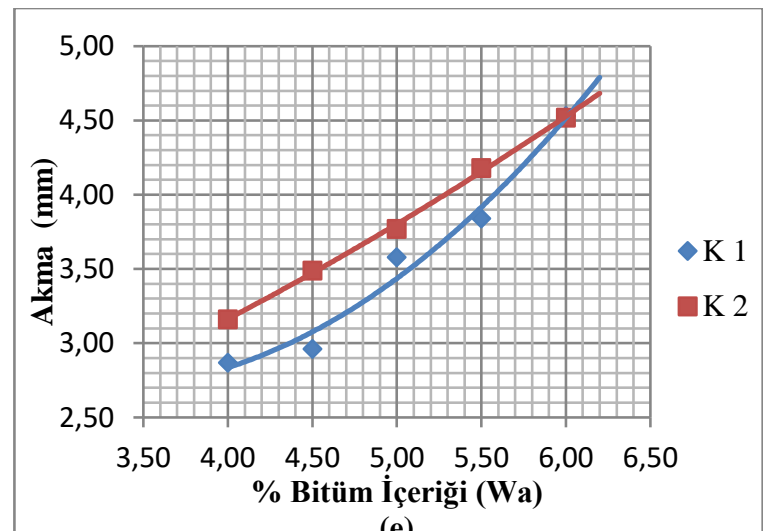

(e)
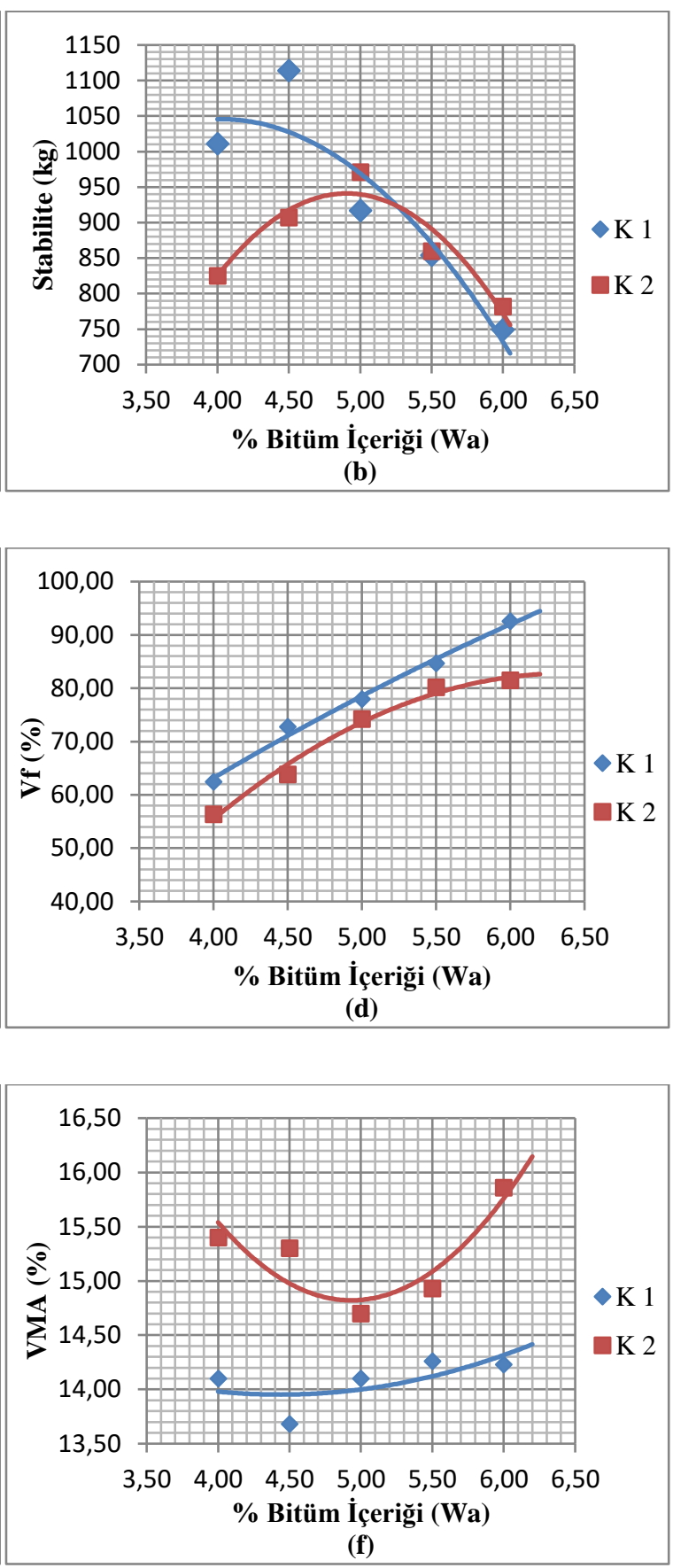

Şekil 3.1. K 1 ve K 2 karışımlarının (a) Dp - Wa grafiği, (b) Stabilite - Wa grafiği, (c) Vh - Wa grafiğgi, (d) Vf - Wa grafiği, (e) Akma - Wa grafiği, (f) VMA - Wa grafiği

K 1 ve K 2 karışımlarının optimum bitüm yüzdeleri sırasıyla \% 4,71 ve \% 4,92 bulunmuştur. K 1 optimum bitüm yüzdesi K 2'ye göre \% 4,28 düşüktür.

B 1 ve B 2 karışımlarına ait Marshall dizayn sonuçları yardımıyla elde edilen Dp - Wa, Stabilite - Wa, , Vh - Wa, , Vf Wa, Akma - Wa, VMA - Wa grafikleri Şekil 3.2'de sırasıyla gösterilmektedir 
European Journal of Science and Technology
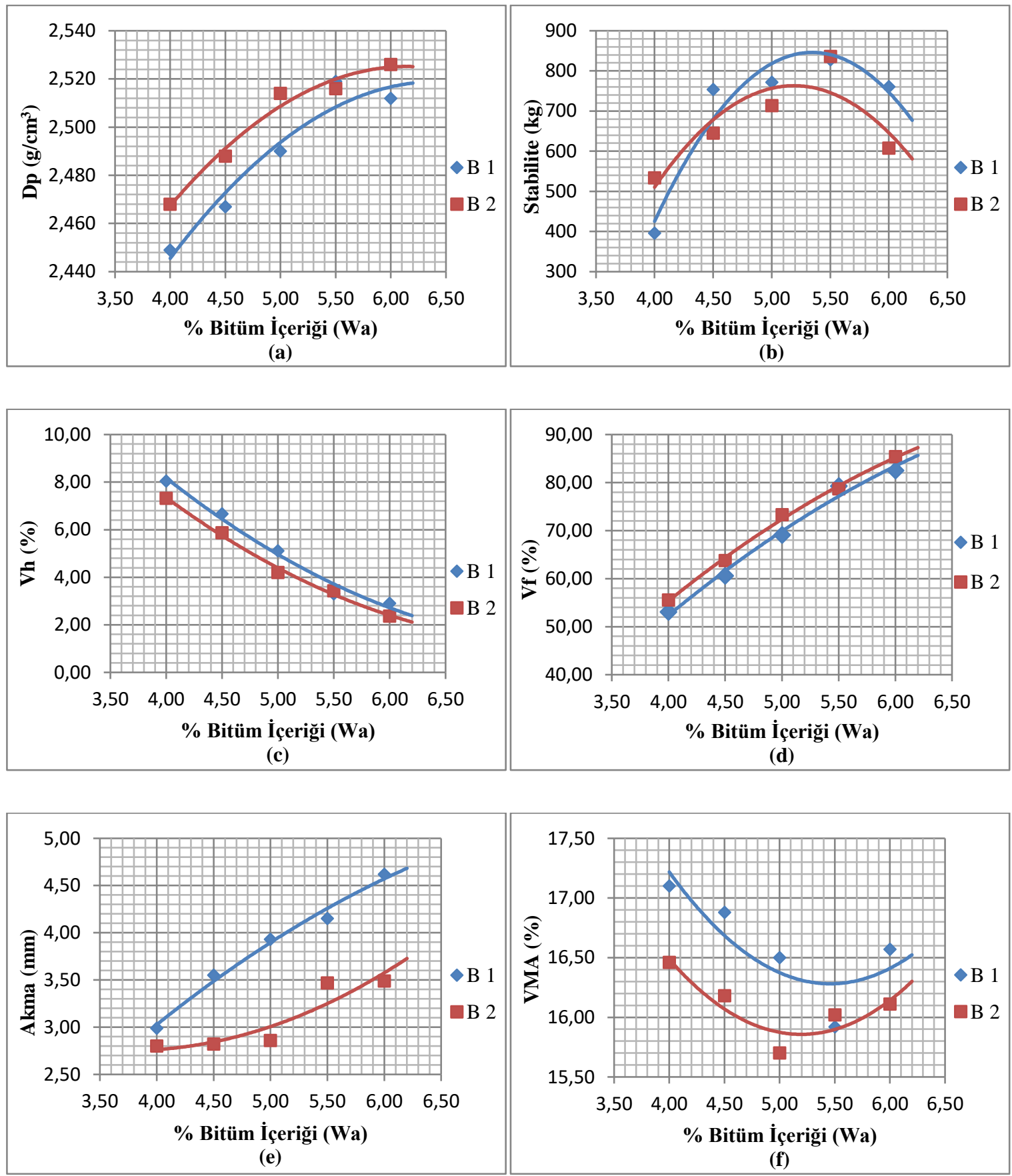

Şekil 3.2. B 1 ve B 2 karışımlarının (a) Dp - Wa grafiği, (b) Stabilite - Wa grafiği, (c) Vh - Wa grafiği, (d) Vf - Wa grafiği, (e) Akma - Wa grafiği, (f) VMA - Wa grafiği

B 1 ve B 2 karışımlarının optimum bitüm yüzdeleri sırasıyla \% 5,33 ve $\% 5,25$ bulunmuştur. B 2 optimum bitüm yüzdesi B 1'e göre $\% 1,5$ düşüktür.
D 1 ve D 2 karışımlarına ait Marshall dizayn sonuçları yardımıyla elde edilen Dp - Wa, Stabilite - Wa, , Vh - Wa, , Vf Wa, Akma - Wa, VMA - Wa grafikleri Şekil 3.3’te sirasiyla gösterilmektedir. 

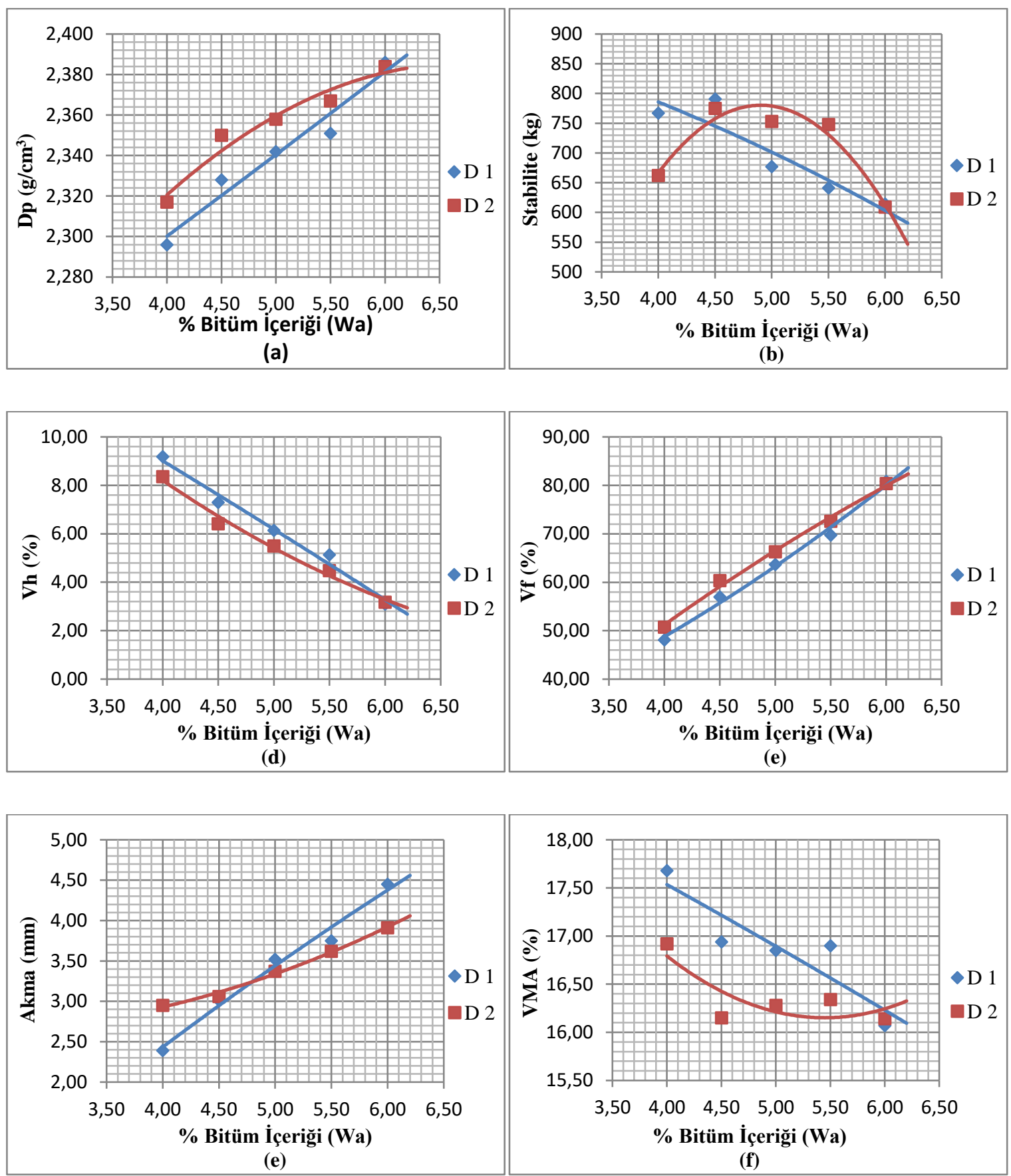

Şekil 3.3. D 1 ve D 2 karışımlarının (a) Dp - Wa grafiği, (b) Stabilite - Wa grafiği, (c) Vh - Wa grafiği, (d) Vf - Wa grafiği, (e) Akma - Wa grafiği, (f) VMA - Wa grafiği

D 1 ve D 2 karışımlarının optimum bitüm yüzdeleri sırasıyla \% 5,29 ve \% 5,19 bulunmuştur. D 2 optimum bitüm yüzdesi D 1 'e göre \% 1,9 düşüktür.
KD 1 ve KD 2 karıșımlarına ait Marshall dizayn sonuçları yardımıyla elde edilen Dp - Wa, Stabilite - Wa, , Vh Wa, , Vf - Wa, Akma - Wa, VMA - Wa grafikleri Şekil 3.4'te sırasıyla gösterilmektedir. 


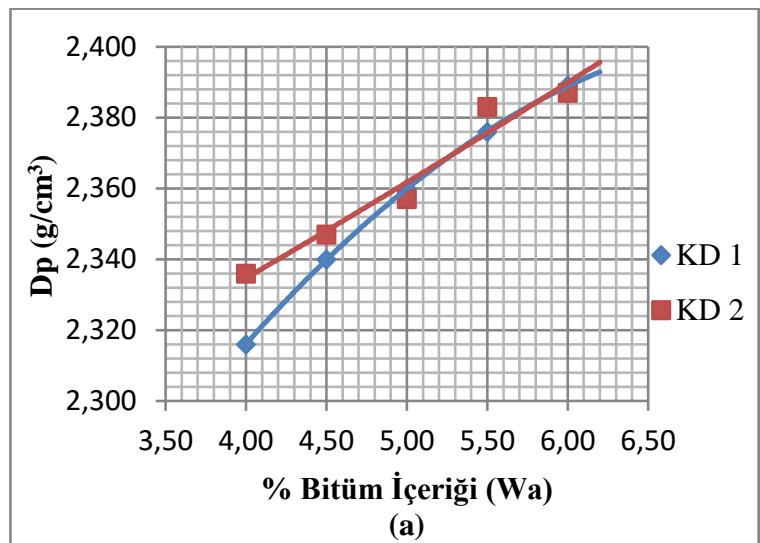

(a)
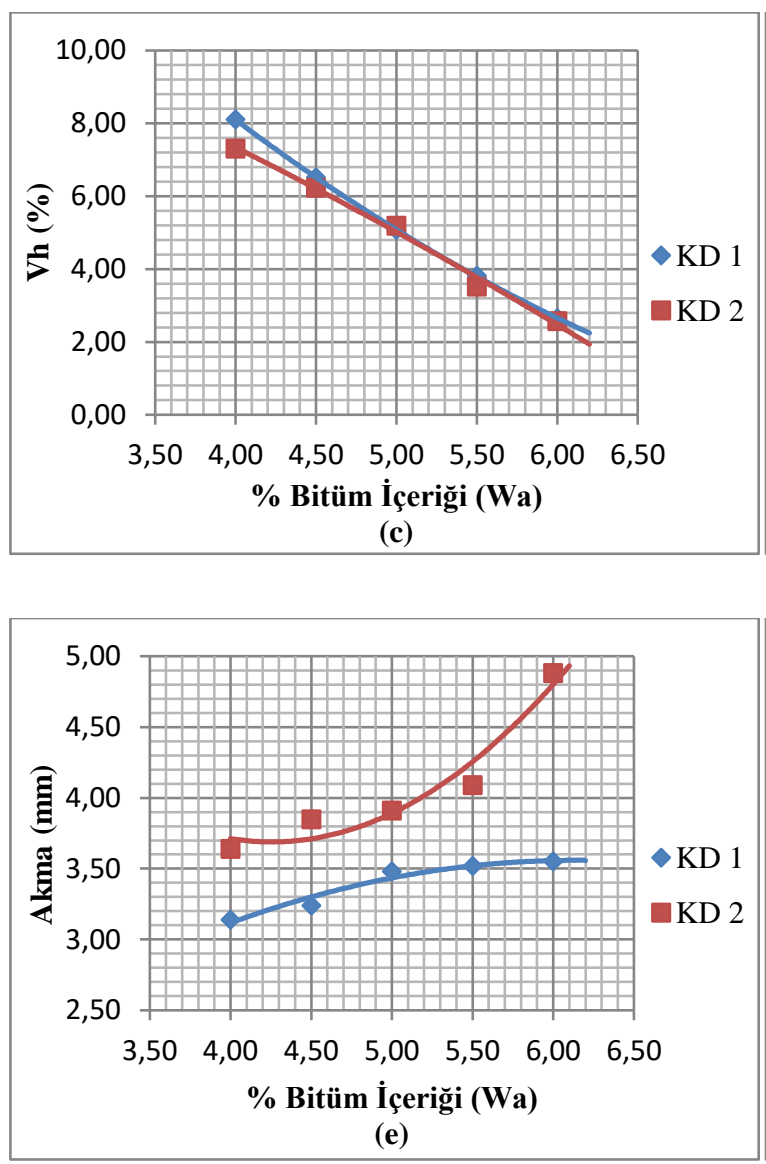

Şekil 3.4. KD 1 ve KD 2 karışımlarının (a) Dp - Wa grafiği, (b) Stabilite - Wa grafiği, (c) Vh - Wa grafiği, (d) Vf - Wa grafiği, (e) Akma - Wa grafiği, (f) VMA - Wa grafiği

KD 1 ve KD 2 karışımlarının optimum bitüm yüzdeleri sırasıyla $\% 5,24$ ve $\% 5,11$ bulunmuştur. KD 2 optimum bitüm yüzdesi KD 1'e göre \% 2,48 düşüktür.

Çalışmada karışımların Şekil 3.1-3.4 arası grafiklerinden yararlanarak hesaplanan optimum bitüm yüzdeleri ve bu
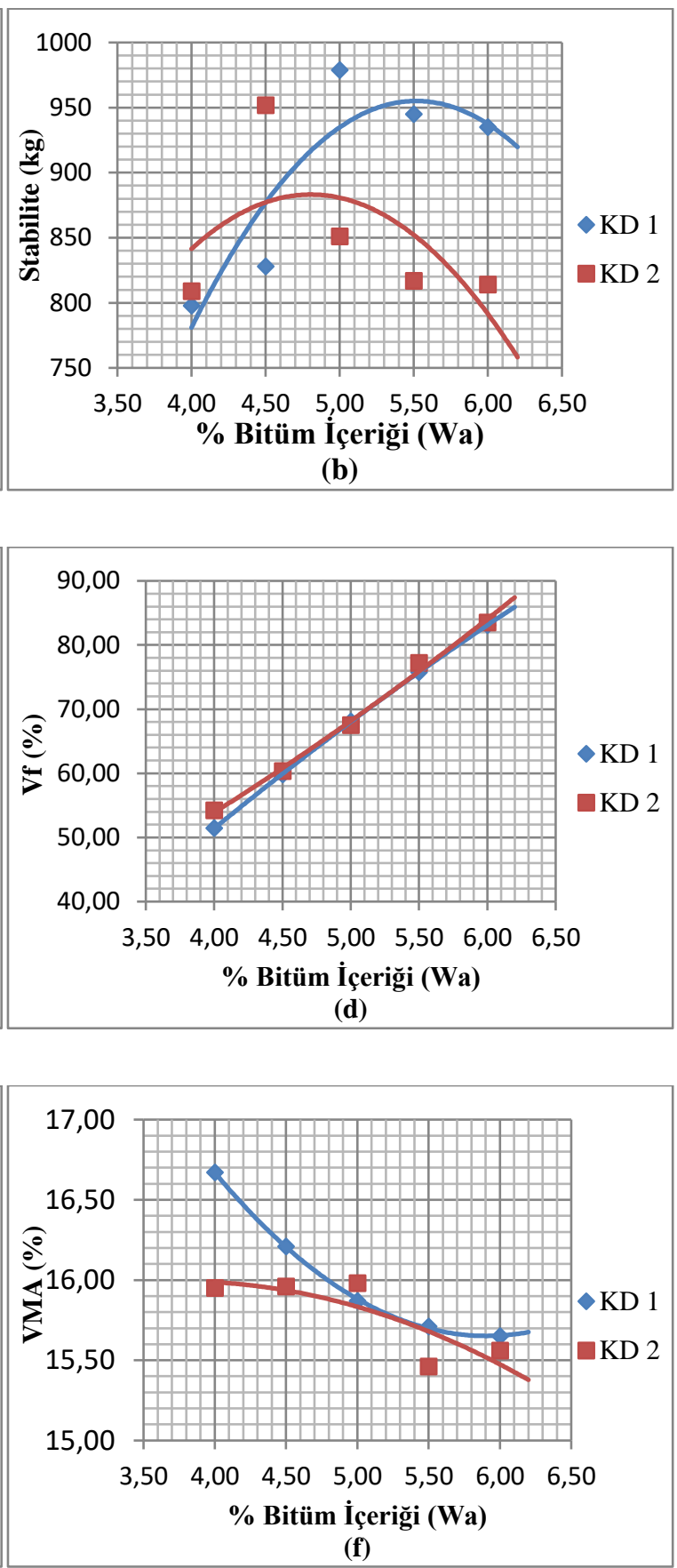

(d)

optimum bitüm yüzdelerine karşılık gelen dizayn parametre değerleri aşağıdaki Şekil 3.5 ve 3.6'da karşılaştırmalı olarak grafikler halinde verilmiştir. 


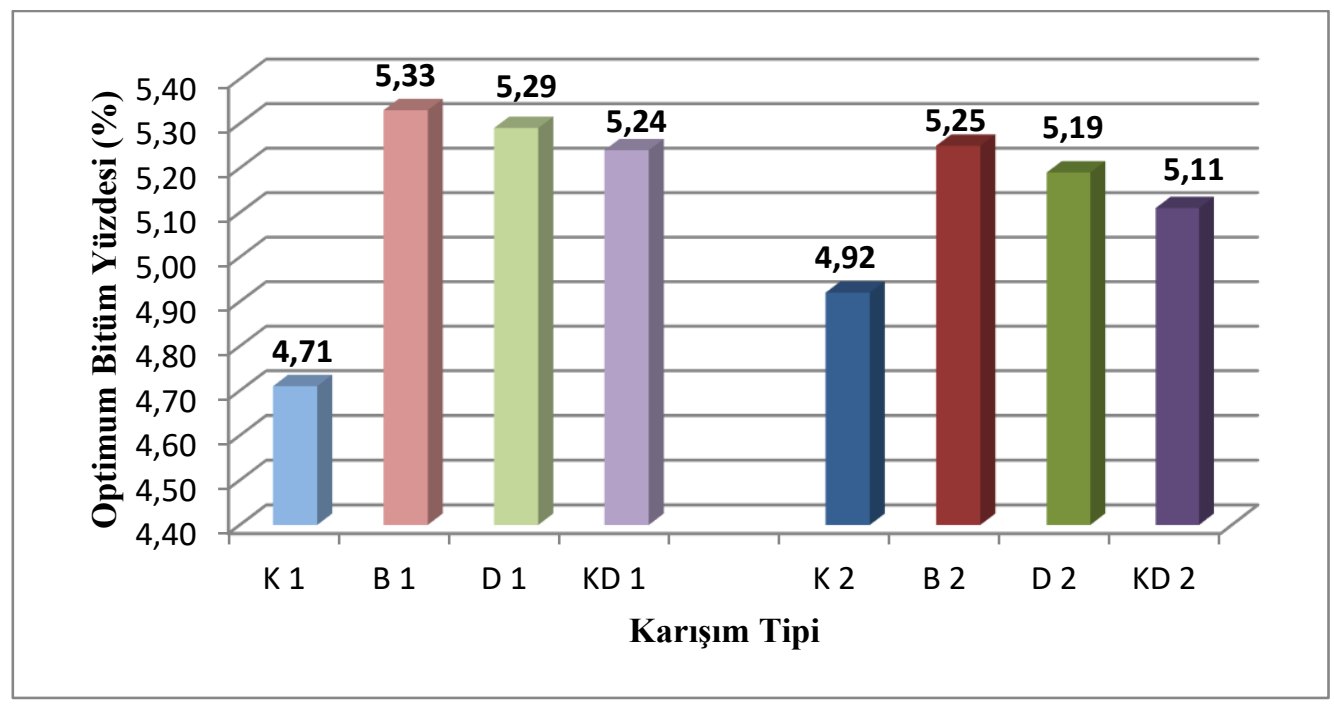

Şekil 3.5. Karışımların optimum bitüm oranlarının karşılaştırılması

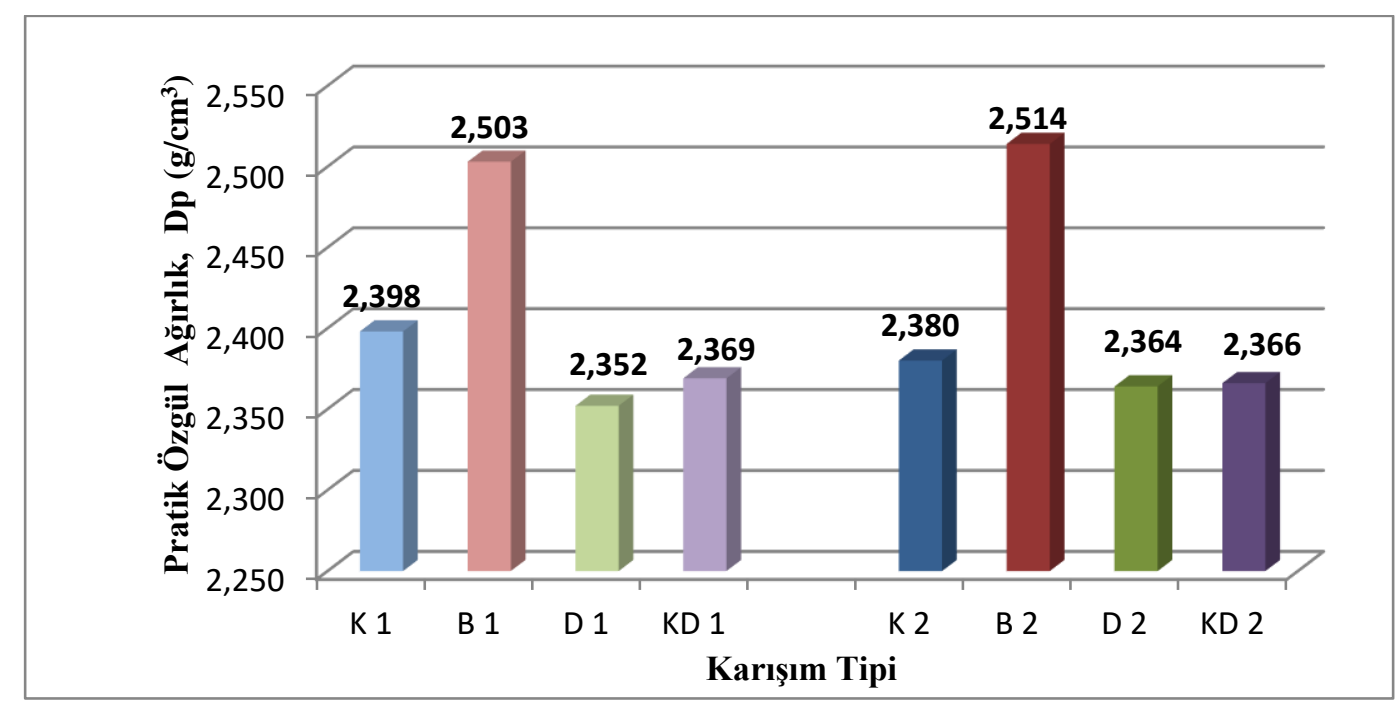

Şekil 3.6. Optimum bitüm oranlarında karışımların pratik özgül ağıllkklarının karşılaştırılması

Aşağıdaki grafiklerde ise optimum bitüm oranlarında stabilite, boşluk, asfaltla dolu boşluk, akma ve agregalar arası boşluk değerleri sırasıyla Şekil 3.7, Şekil 3.8, Şekil 3.9, Şekil 3.10 ve Şekil 3.11'de verilmiştir. 


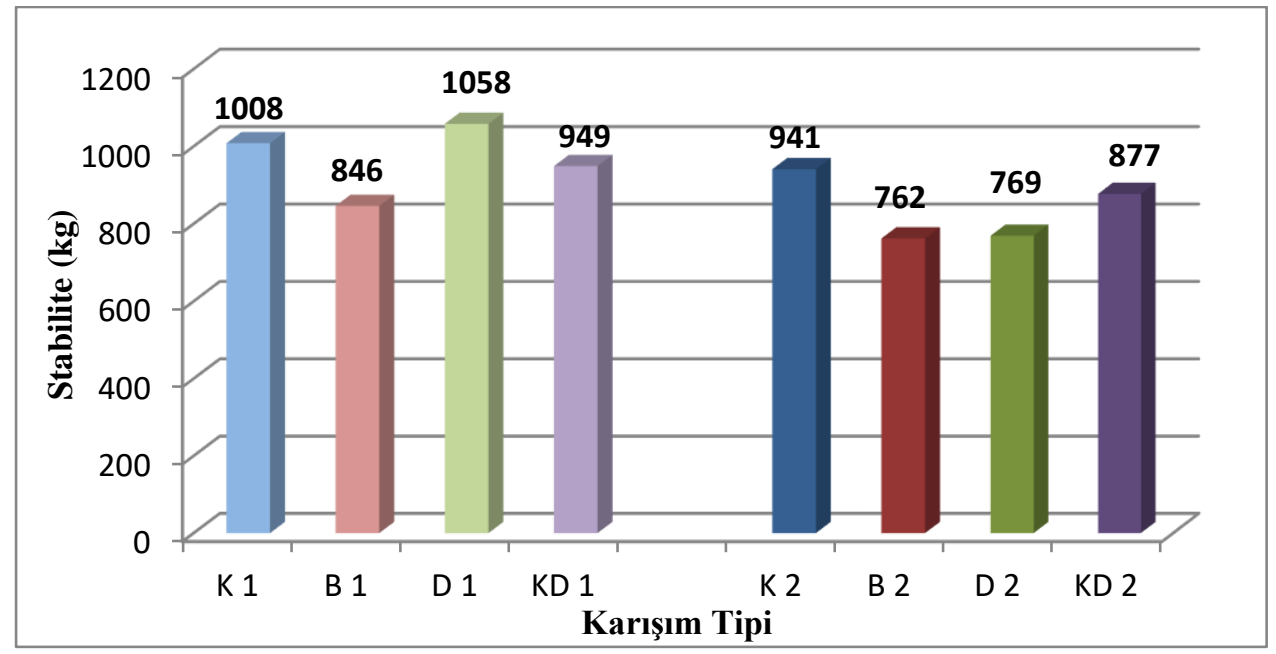

Şekil 3.7. Optimum bitüm oranlarında karışımların stabilite değerlerinin karşılaştırılması

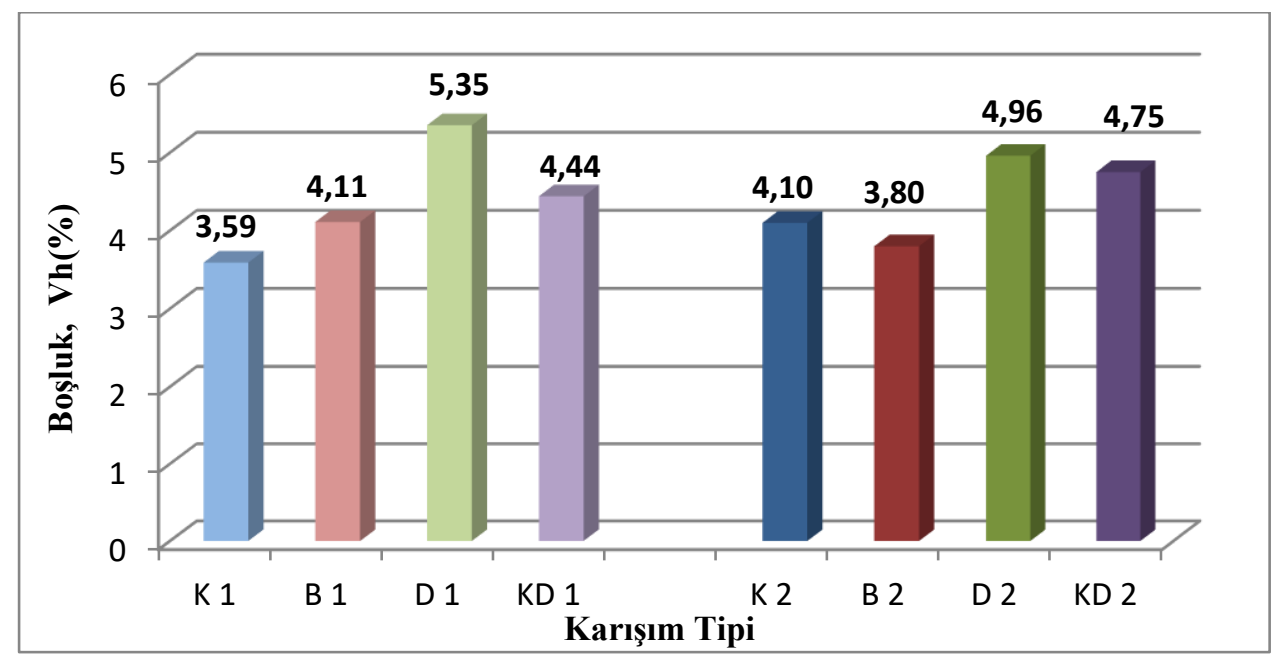

Şekil 3.8. Optimum bitüm oranlarında karışımların boşluk oranlarının karşılaştırılması

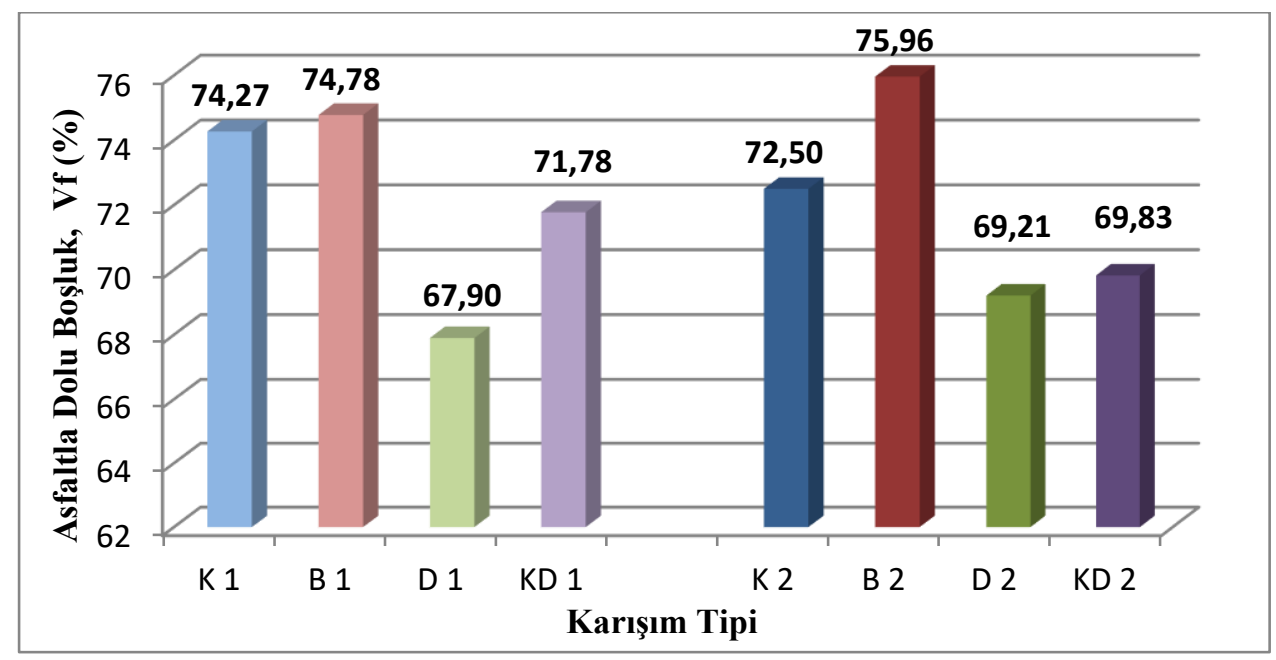

Şekil 3.9. Optimum bitüm oranlarında karışımların asfaltla dolu boşluk yüzdelerinin karşılaştırılması 


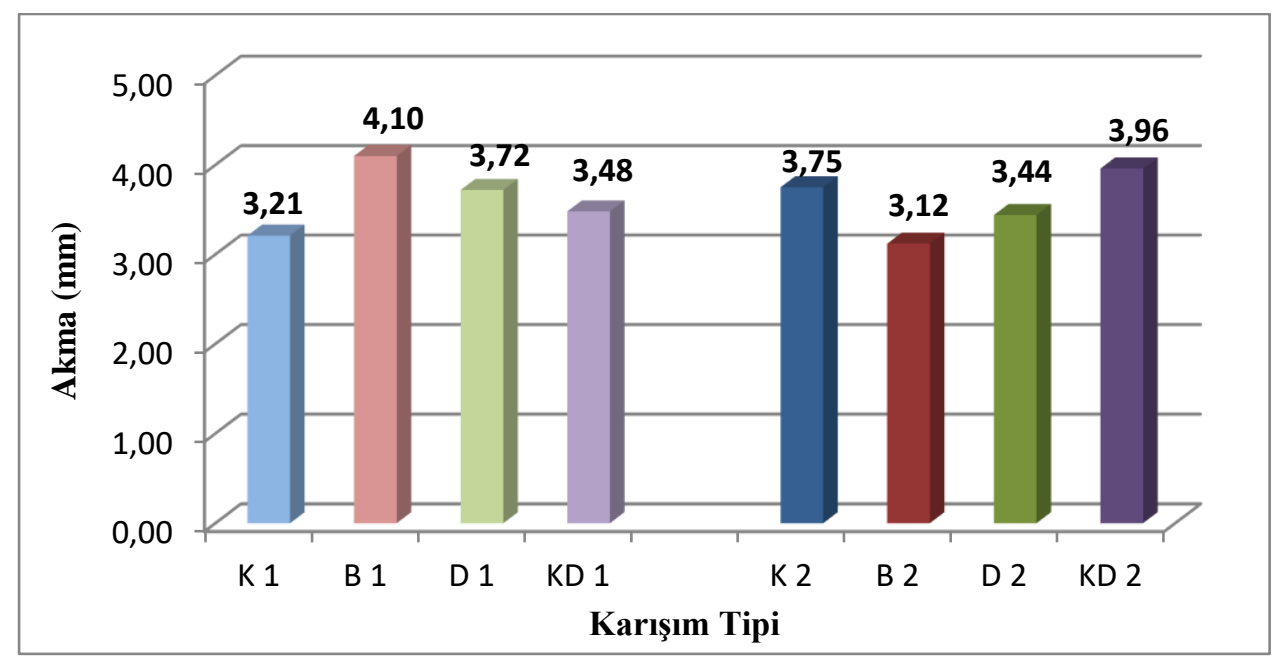

Şekil 3.10. Optimum bitüm oranlarında karışımların akma değerlerinin karşılaştırılması

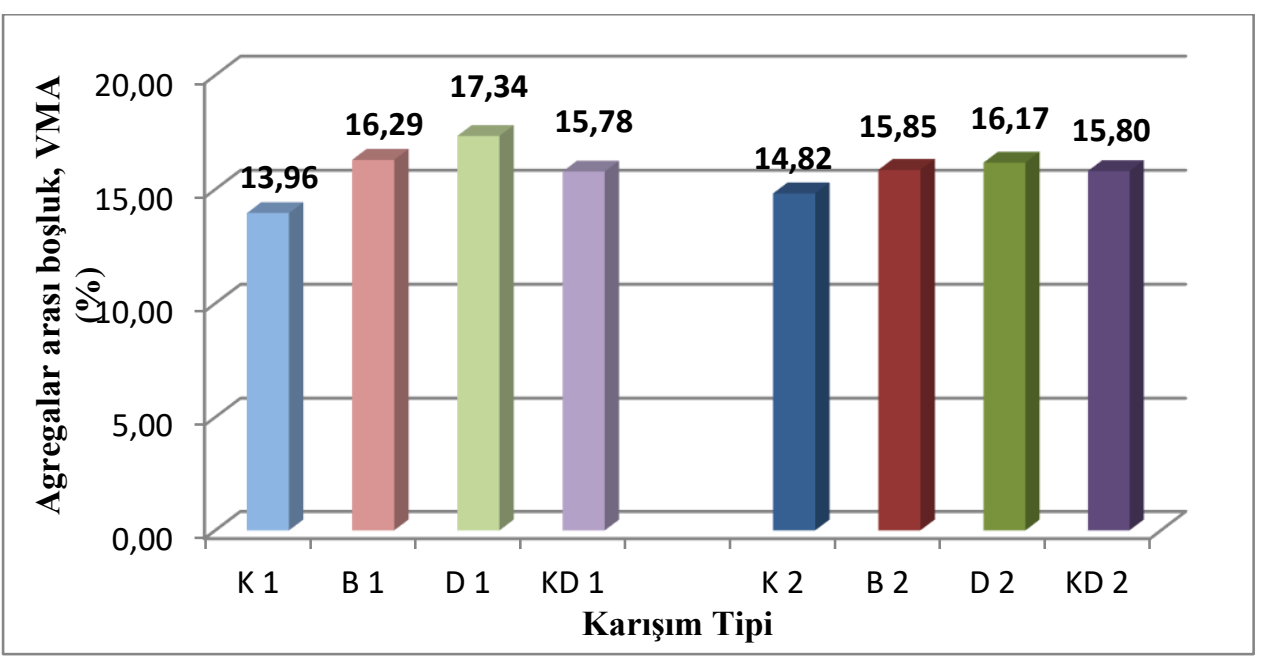

Şekil 3.11. Optimum bitüm oranlarında karışımların agregalar arası boşluk yüzdelerinin karşılaştırılması

\section{Sonuçlar}

$\mathrm{Bu}$ çalışma, değişik tipteki agrega ve bağlayıcının sıcak karışım asfaltın mekanik özelliklerine etkisi araştırmak amacıyla yapılmıştır. Bu doğrultuda yapılan Marshall dizayn deneylerinde elde edilen bulgulara göre aşağıdaki sonuçlara varılmıştır.

- $\mathrm{K} 1, \mathrm{~K} 2, \mathrm{~B} 1, \mathrm{~B} 2, \mathrm{D} 1, \mathrm{D} 2, \mathrm{KD} 1$ ve $\mathrm{KD} 2$ karışımların optimum bitüm yüzdeleri sırasıyla $\% 4,71$, $\% 4,92, \% 5,33, \% 5,25, \% 5,29, \% 5,19, \% 5,24$ ve $\%$ 5,11 bulunmuștur. En yüksek optimum bitüm oranları agrega grubu bazalt olan B 1 ve B 2 karışımlarında (sırasıly \% 5,33 ve \% 5,25 oranları ile) elde edilmiştir. En düşük optimum bitüm yüzdeleri ise agrega grubu kalker olan K 1 ve K 2 karışımlarında (sırasıyla \% 4,71 ve $\% 4,92$ oranları ile) elde edilmiştir. Burada bazaltlı karışımların daha fazla bitüme gereksinim duyduğu ve bundan dolayı optimum bitüm oranlarının diğer karışımlara göre yüksek çıktığı söylenebilir.

- 50/70 penetrasyonlu bitümlü bağlayıcı kullanılan karışımlarda en yüksek stabilite değeri dere malzemeli karışımda (D 1) elde edilmiştir (1058 kg). 160/220 penetrasyonlu bitümlü bağlayıcı kullanılan karışımlarda en yüksek stabilite değeri ise kalkerli karışımda (K 2) elde edilmiştir (941 kg). Tüm karışımların optimum bitüm oranlarında elde edilen sonuçlara göre 50/70 penetrasyonlu bitümlü bağlayıcı kullanılan karışımların stabilite değerleri, 160/220 penetrasyonlu bitümlü bağlayıcı kullanılan karışımların stabilite değerlerine göre yüksek çıkmıştır. Fakat elde edilen tüm sonuçlar şartname sınır şartları sağlamıştır.

- Optimum bitüm oranlarında en yüksek pratik özgül ağırlıklar (Dp) agrega grubu bazalt olan B 1 ve B 2 karışımlarında elde edilmiştir. $\mathrm{Bu}$ değerler sırasıyla $2,503 \mathrm{gr} / \mathrm{cm}^{3}$ ve $2,514 \mathrm{gr} / \mathrm{cm}^{3}$ 'tür. Diğer karışımların optimum bitüm oranlarında pratik özgül ağırlıkları birbirine yakın çıkmıştır. Pratik özgül ağırlık değerlerinin yüksek olması bitümlü kaplamalarda geçirimsizliğin, yaşlanma, soyulma ve sökülme bozulmalarına karşı dayanımın artışında daha iyi sonuçlar vereceği düşünülmektedir. Bazaltlı karışımların pratik özgül ağırlıklarının yüksek oluşu agrega özgül ağırlık değerlerinin kalker ve dere 
malzemesine göre yüksek oluşundan kaynaklandığı düşünülmektedir.

- B 1, D 1, KD 1, K 2, D 2 ve KD 2 karışımlarının boşluk oranları (Vh, (\%)) optimum bitüm oranlarında şartname sınır şartları (4-6 arası) sağlamaktadır. K 1 ve B 2 karışımlarının optimum bitüm oranlarındaki boşluk yüzdeleri şartname sınır değerinin altında kalmıştır. Bu durumda $K 1$ ve B 2 karışımları özellikle sıcaklığın iyice yükseldiği yaz aylarında bağlayıcı bitümün hacminin artması sonucu boşlukların tamamen dolarak kusmanın gerçekleşebileceği söylenebilir. Boşluk şartnamede belirtilen sınırlarının üstüne çıkarsa stabilitede düşme ve kaplamada erken bozulma görülebilir.

- Asfaltla dolu boşluk, karışımların plastisite, durabilite ve sürtünme katsayısı gibi özellikleri kontrol etmektedir. $\mathrm{Bu}$ da çevresel etkilere karşı dayanım açısından önemli bir özelliktir. Optimum bitüm oranlarında asfaltla dolu boşluk oranları (Vf, (\%)) değerlendirildiğinde B 2 hariç diğer tüm karışımların sonuçları şartname sınır şartları $(65-75$ arası) sağlamıştır. B 2 karışımının asfaltla dolu boşluk yüzdesi $(\% 75,86)$ maks. sınır şartın üzerinde çıkmış fakat çok yakın sonuç elde edilmiştir.

- Karışımların optimum bitüm oranlarında akma değerleri (B 1 hariç) şartname sınır şartları (2-4 arası) sağlamıştır. B 1 karışımının akma değeri 4,10 olup maks. sınır şartın üzerinde çıkmış fakat çok yakın sonuç elde edilmiştir. Akma değerinin yüksek olması, kaplamanın dayanımını düşürerek ve yük altında deforme olmasina neden olabilir.

- Optimum bitüm oranlarında agregalar arası boşluk yüzdeleri (VMA, (\%)) kıyaslandığında kalkerli karışımların (K 1ve K 2) şartname sınır şartları (13-15 arası) sağladığı görülmekte olup diğer karışımlardan elde edilen sonuçlarda sınır şartlar sağlanamamış ve yüksek çıkmıştır. Agregalar arası boşluk miktarının fazla olması karıșımların stabilite değerlerini olumsuz yönde etkiler. Karışım içerisindeki agregalar arası boşluk miktarının azaltılması için karışımı oluşturan gradasyon limitlerinde değişim yapılması veya karışımın sıkıştırılmasında uygulanacak enerjinin arttırılması ile sağlanabileceği önerilebilir. Fakat bu değişikliklerin etkileri ayrıca çalışılıp incelenmelidir.

- Karışımlar ekonomik bakımdan değerlendirildiğinde aşağıdaki sonuçlara ulaşılmıştır.

1. Stabilite karışımlar için önemli bir faktördür. Eğer K 1 karışımının boşluk oranı, min. şartname sınırının üzerine çıksa idi, K 1 karışımı K 2'ye göre daha tercih edilebilirdi. Ayrıca ekonomik olarak da (\% 4,71 bitüm oranı ile) daha uygun olabilirdi.

2. Ekonomi ve stabilite bakımından bakıldığında (\% 5,33 bitüm oranı ile) B 1 karışımı B 2 karışımına göre daha uygundur. Ayrıca B 1 karışımının Vh ve akma değerleri çok küçük oranda sınır değerin üzerine çıkmıştır.

3. Ekonomik olarak D 1 ve D 2 karışımları yakın değerdedir. VMA değerleri dikkate alınmadığında, stabilite bakımından düşünüldüğünde D 1 karışımı D 2'ye göre çok daha iyi sonuç vermiştir.

4. Stabilite bakımından KD 1 karışımı daha iyi durumdadır. Ancak (VMA dikkate alınmazsa) KD 2, stabilitesi minumum şartname sınır değerinin üzerinde çıktığından ve daha az bitüm ihtiva ettiğinden KD 1'e tercih edilebilir.

Marshall dizayn deneyleri sonucunda ekonomik açıdan en iyi olan K 2 karışımı optimum bitüm oranı \% 4,92 olup aynı zamanda stabilite, akma, Vh, Vf ve VMA için verilen şartname sınır şartların hepsini sağlamıştır. Bundan dolayı da en iyi sonuçlar K 2 karışımında elde edilmiş ve tercih sebebidir.

\section{KAYNAKLAR}

[1]. Elmac1, A., 2011. Asfalt Betonunda Granit Aritma Çamurunun Filler Malzemesi Olarak Kullanılabilirliğinin Araştırılması, Yüksek Lisans Tezi, Afyon Kocatepe Üniversitesi, Fen Bilimleri Enstitüsü, Afyon.

[2]. Akpolat, M., 2014. Ilık Karışım Katkısının Bitüm ve Taş Mastik Asfalt Kaplamaya Etkisinin Araştırılması, Yüksek Lisans Tezi, Frrat Üniversitesi, Fen Bilimleri Enstitüsü, Elazığ.

[3]. Avc1, E., 2009. Sicak İklimli Bölgelerde Kullanılan Asfalt Betonu Karışım Değişkenlerinin Kaplama Tabakası Performansına Etkisi, Yüksek Lisans Tezi, Süleyman Demirel Üniversitesi, Fen Bilimleri Enstitüsü, Isparta.

[4]. Jones, R., Modifiers for Asphalt Concrete, Air Force Engineering and Service Center Project, No: ESL-TR88-32, 93 p., 1990.

[5]. Bagampadde, U., Isacsson, U., Kiggundu, B.M., 2005. Influence of Aggregate Chemical and Mineralogical Composition on Stripping in Bituminous Mixtures. International Journal of Pavement Engineering, 6, 229239.

[6]. Kök, B. V., Kuloğlu, N., 2008. İki Aşamalı Karıștırma Yönteminin Bitümlü Sıcak Karışımların Mekanik Özelliklerine Etkisi. Süleyman Demirel Üniversitesi Fen Bilimleri Enstitüsü Dergisi, 12-1 (2008),35-48.

[7]. Tunç, A., 2004. Esnek Kaplama Malzemeleri El Kitab1, Asil Yayın Dağıtım, 352 s.

[8]. Akbulut, H., Gürer, C., 2006. Atık mermerlerin Asfalt Kaplamalarda Agrega Olarak Değerlendirilmesi, IMO Teknik Dergisi, 3943-3960, Yaz1 261.

[9]. Al-Hourani, M.A. and Khedawi, T.S., 1998. Effect of Polymer and Limestone Dust On The Durability of Asphalt Paving Mixtures.

[10]. Karayolları Teknik Şartnamesi, 2013. KGM Yayını, Ankara.

[11]. Kizirgil, M.E., 2013. Stiren-Butadien-Stiren ve Uçucu Külün Birlikte Kullanılmasının Bitümlü Sicak Karışımların Mekanik Özelliklerine Etkisi, Doktora Tezi, Fırat Üniversitesi, Fen Bilimleri Enstitüsü, Elazı̆̆.

[12]. TS 3720, 1983. Bitümlü Kaplama Karışımlarının Hesap Esaslar1-Marshall ve Hubbart- Field Metotları ile, Türk Standartları Enstitüsü, Ankara. 